\title{
RECONNAISSANCE EVALUATION OF A POTENTIAL FUTURE SINKHOLE USING INTEGRATED SIMPLE SURFACE GEOPHYSICS AND SURFACE MONITORING POINTS
}

\author{
Michael L. Rucker, Sean Hulburt \\ AMEC Environment \& Infrastructure, Inc., 4600 East Washington St., Suite 600, Phoenix, AZ 85034, \\ michael.rucker@amec.com,sean.hulburt@amec.com
}

\section{Mark D. Edwards}

Ninyo \& Moore, Geotechnical \& Environmental Sciences Consultants, 3202 East Harbour Drive, Phoenix, Arizona 85034,.mark.edwards@ninyoandmoore.com

\begin{abstract}
The Arizona Department of Water Resources (ADWR), using satellite-based Interferometric Synthetic Aperture Radar (InSAR) to assess subsidence in parts of Arizona, has identified several subsidence features consistent with potential future sinkholes in an area with several hundred natural evaporite karst depressions or sinkholes. An initial reconnaissance geophysical subsurface evaluation at the most significant of these features was performed in September 2012. Subsurface geo-material strength profiles to depths commonly in excess of 100 meters can be obtained using relatively simple, unobtrusive and inexpensive seismic surface wave (s-wave) geophysical methods such as Refraction Microtremor (ReMi). ReMi can utilize ambient ground vibrations from natural sources or deliberate sources such as vehicle traffic or construction equipment. Shallow ReMi has been applied in conjunction with seismic refraction to characterize shallow subsurface material strength as part of assessing the potential for collapse of an evaporate brine cavern into a large sinkhole in southeast New Mexico, but had not been specifically applied to assessing subsurface conditions in the deeper subsurface above and in the vicinity of a possible impending sinkhole.
\end{abstract}

Two deep ReMi surface wave soundings and two resistivity soundings using the Wenner array method were performed, one each within and outside of the extent of current subsidence as derived from the InSAR. Surface wave velocity profiles indicated relatively low velocity materials extending to depths of 36 to 50 meters; surface wave velocities within the subsidence zone were lower (weaker material) than surface wave velocities outside the zone. The underlying horizon had high surface wave velocities indicating relatively competent rock. Deep resistivity soundings indicated possible lithologic change at depths of roughly 120 to 150 meters. Results of this work, including interpretations and assessments of knowledge gained, practical additional assessment work that could be performed, and some as yet unanswered questions are presented.

\section{Introduction}

A relatively large region of evaporite karst, primarily developed above bedded halites of Permian age, is present south of Holbrook, Arizona (Figure 1). As described by Neal et al. (1998), over 500 karst features such as sinkholes, depressions, fissures and the like are present along and around a roughly 100-km long dissolution front coincident with a structure named the Holbrook Anticline. Recently, the Interferometric Synthetic Aperture Radar (InSAR) group within the

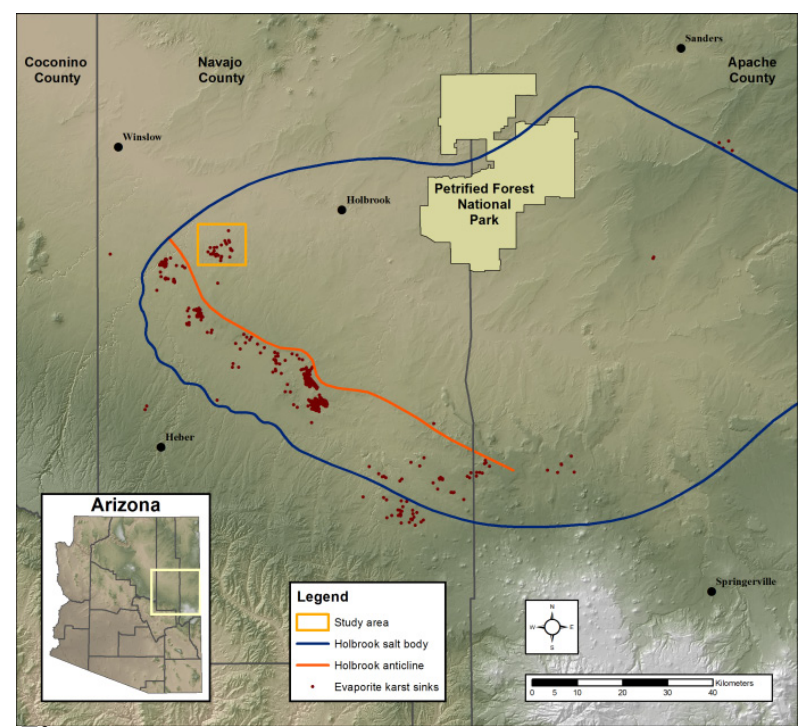

Figure 1. From Conway and Cook (Figure 1, 2013), InSAR study area in relation to the Holbrook salt body, Holbrook anticline and known evaporite karst features. 
Arizona Department of Water Resources (ADWR) acquired and processed available satellite-based InSAR data for the region in preparation for monitoring potential future subsidence related to proposed potash mining in the vicinity of Petrified Forest National Park (Conway and Cook, 2013). Several areas of active subsidence were identified in the interpreted InSAR results. The most significant of these features is located primarily in the western portion of Section 3 of Township T16N-R18E. An InSAR interferogram indicating active subsidence at this feature is shown is Figure 2. The sink feature is located in a relatively isolated area, with no known potential geohazard impacts, and thus no pressing public or private safety or economic needs for monitoring or engineering mitigation. The 'Section 3' feature was selected by the Arizona Land Subsidence Interest Group (AzLSG) for further study on a volunteer basis to document observable geologic behaviors or changes that may contribute to knowledge of subsidence and sinkholes.

Part of the study initiated involves measurement of ground displacement. InSAR-derived subsidence information is an interpretation of recent vertical subsidence at the Section 3 feature. ADWR personnel have established Global Positioning Survey (GPS) monuments at the feature and have conducted initial

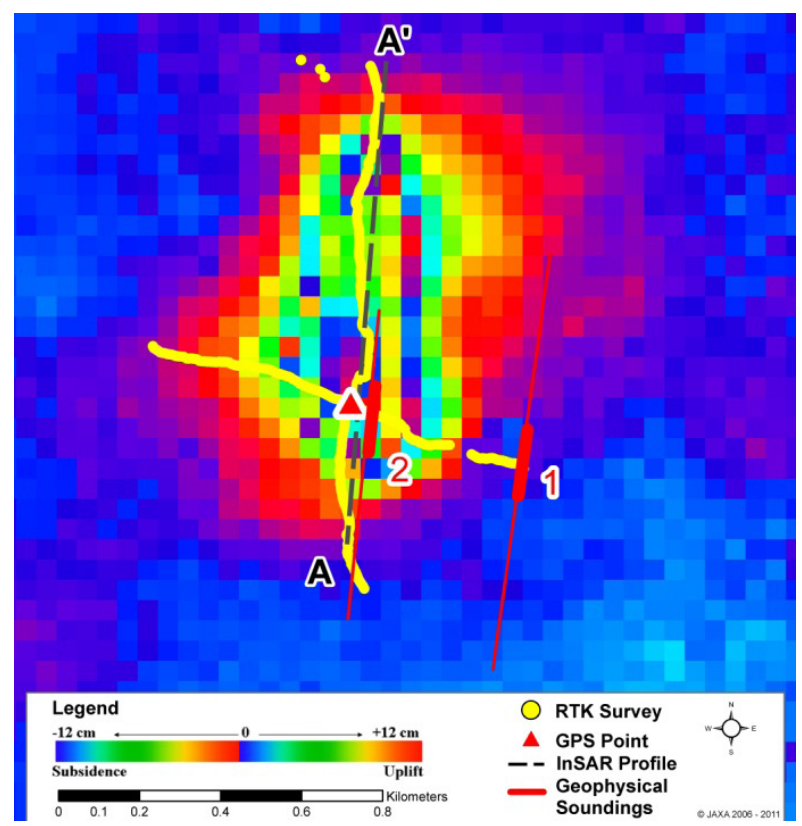

Figure 2. L-band InSAR interferogram (courtesy $B$. Conway, ADWR) of Section 3 feature showing extent of local subsidence, RTK survey, subsidence profile $A-A^{\prime}$ and geophysical sounding locations. surface elevation profiles to ground-truth future InSAR results. Open ground fissures provide evidence of local horizontal ground displacements at various subsidence feature locations. Several eyebolt monument pairs have been set at open fissures so that future changes in fissure width can be monitored over time.

This paper addresses initial preliminary geophysical characterization of the subsurface at the active Section 3 subsidence feature. Subsurface material parameters that might be characterized include depths or thicknesses of the geologic formations and generalized aspects of geologic material strength. Karst activity can commonly be related to loss of strength in a geo-material mass. Above a carbonate or evaporite dissolution zone, enhanced weathering and fracturing, or even collapse, of the overlying rock mass reduces the overlying rock mass strength. Rock mass strength is related to seismic velocity and can be assessed using seismic methods. In addition to lithologic changes, electrical resistivity may provide information concerning groundwater or changes in rock mass weathering that may be related to karst activity.

Evaporite karst may impact or develop within a subsurface profile that extends to hundreds of meters in depth. Exploratory drilling to such depths can be prohibitively expensive and inefficient in terms of overall site characterization and coverage over a large area. Large-scale geophysical characterization, including 2-D reflection profiling, has been performed recently in the Holbrook basin to support exploration and characterization of minable potash deposits. Although such methods may provide excellent subsurface characterization, the cost for noncritical applications can be prohibitive. Refraction microtremor (ReMi) surface wave seismic and Wenner array resistivity provide means to perform simple, lowcost reconnaissance surface geophysics capable of providing useful subsurface characterization to depths in excess of 100 meters.

Although the Section 3 feature is not associated with a current or pressing hazard, karst-like geohazard behaviors have impacted industrial activity in the region. Neal et al. (1998) summarize historic effluent release events in 1963, 1984 and 1995 into fissures or karst-like features in the Holbrook Anticline area. These events occurred before InSAR remote-sensing technology was available to identify areas of active subsidence. Incorporating 
InSAR with other characterization and monitoring procedures may significantly enhance the ability to identify and mitigate some subsidence and sinkhole hazards.

\section{Geologic Setting}

Subsidence, sinkhole and karst activity in the area is presumed to be driven over geologic time by dissolution of evaporite deposits within the Holbrook salt body. The Holbrook salt body is located in the southern margin of the Colorado Plateau. As summarized by Neal et al. (1998), rocks of Permian Age, including the Coconino sandstone and salt deposit bearing Corduroy member of the Sedona Group, are relevant in the study area. About $10 \mathrm{~km}$ to the west of the Section 3 feature, a group of large sinkholes known as the McCauley Sinks, are overlain by younger Kaibab limestone that serves as a thin near-surface cap at those sinkholes. However, the Kaibab pinches out east of the McCauley Sinks, and Coconino sandstone is left as the upper subsurface member at the Section 3 feature. Johnson (1962) describes the Coconino in the nearby Snowflake-Hay Hollow area as "In places the sandstone is tightly cemented with silica, but the degree of cementation varies considerably from place to place as well as vertically in any given section." Without well log control in the vicinity, the local thickness of the Coconino is unknown. Based on limited historic geophysical log data in the region (Figure 4 in Neal et al. 1998), it may be about 200 meters or less in thickness at Section 3.

Underlying the Coconino sandstone is the Corduroy Member of the Sedona Group. Included in the Corduroy Group are shales, anhydrites, halite (salt), and salt and shale. Dissolution of salt in the Corduroy Member is considered to be the primary subsidence mechanism for generating karst. Neal et al. (1998) indicate that dissolution has likely been continuing since the Pliocene. The Holbrook anticline, which involves at least the rock profile above the Corduroy Member salt, is more than 10 $\mathrm{km}$ to the southwest from the Section 3 feature. Significant bedrock fracturing activity, providing concentrated pathways for groundwater to access soluble formations, tends to be concentrated closer to the anticline. It is also anticipated that bedrock overlying zones of large-scale dissolution would tend to be fractured or perhaps even brecciated as the rock column subsides downward while dissolution progresses.

Historic and recent depths to groundwater in stock wells located about $2 \mathrm{~km}$ east of the Section 3 feature, are recorded in ADWR databases (ADWR, 2012). A depth to groundwater of 91 meters is recorded for Well A(1618)02ACB in 1946. Depths to groundwater at Well A(16-18)02BAD at elevation 1,664 meters above mean sea level (amsl) are reported to be about 112, 120 and 121 meters in 1968, 1975 and 2009, respectively.

\section{Surface Elevation and Subsidence}

The regional ground surface trend in this portion of the Holbrook Basin is a gradual slope towards the Little Colorado River to the north-northeast. That regional trend is apparent in the south to north RTK survey profile performed by ADWR (Figures 2 and 3).

A local ground surface elevation trend is included in Figure 3. This trend assumes that the RTK survey southern and northern ends are consistent with a ground surface trend in the absence of local subsidence. The RTK surface elevation survey indicates that subsidence has occurred in the southern portion of the Section 3 feature. Assuming a uniform grade prior to local subsidence activity, possible subsidence could have been as great as 12 meters or more over a profile distance of about 200 meters. Possible subsidence is reduced towards the north, and is typically 2 meters or less compared to the no local subsidence trend.

The InSAR current subsidence pattern covering December 2006 to February 2011 presented at profile A-A' is closely related to, but significantly different from the apparent pattern of historic subsidence derived from the RTK survey. The southern end of the RTK profile indicates a steep increase in apparent subsidence over

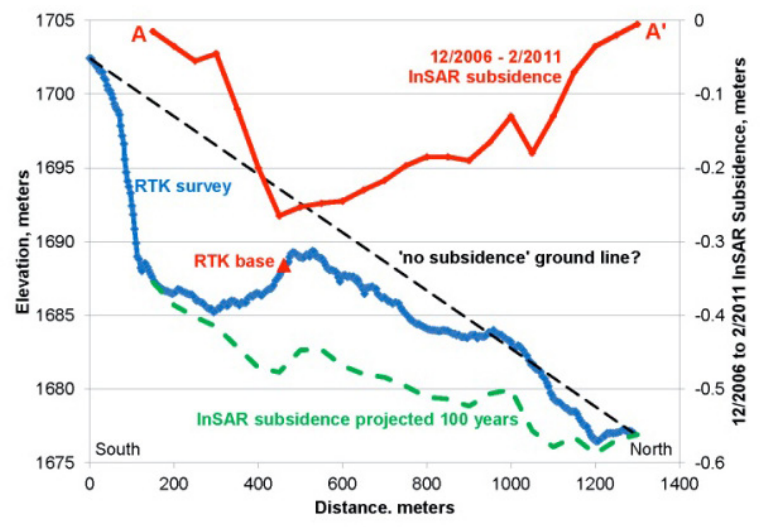

Figure 3. Comparison of RTK surface elevation survey with L-band InSAR-derived subsidence on a south to north profile through Section 3 feature (Figure 2). 


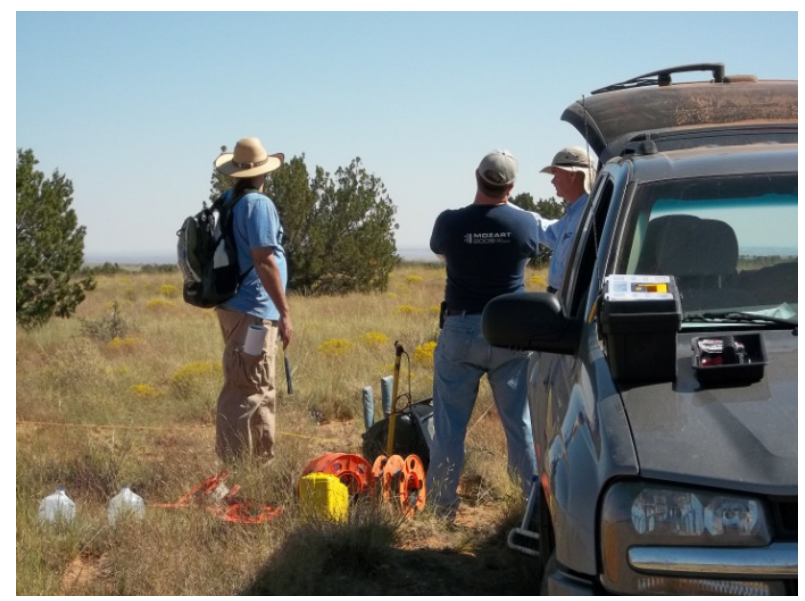

Figure 4. Resistivity equipment including meter (yellow box), electrode cable spools and water jugs; water is added at electrodes to improve contact with ground.

a distance of about 100 meters. InSAR-derived current subsidence in that area is negligible. The area of greatest apparent subsidence, typically about 12 meters, along the next 200 meters of RTK survey profile, has only minor InSAR derived subsidence up to about 0.05 meters in four years. However, the apparent subsidence rapidly decreases at the northern edge of this deep local area. Where the measured apparent intra-basin subsidence is nearing its minimum, the current active subsidence is near its maximum. The point of highest InSAR-derived subsidence is at the northern lip of the local apparent subsidence area. A benchmark was established in this area for future GPS elevation measurements and to serve as an RTK survey base. Active subsidence then gradually tapers off to the north. If the current rate of subsidence is projected 100 years into the future, the local deep subsidence area would increase in size to the north, but the maximum subsidence depth would not significantly increase.

\section{Anticipated Geophysical 'Targets'}

Anticipated geophysical measurement results or targets can be developed based on the geologic setting, apparent local subsidence pattern and magnitude, and current subsidence trend. Confirmation or refutation of anticipated geophysical results would assist the process of understanding and characterizing details of conditions and mechanisms driving continued development of karst in this area. Deep sounding electrical resistivity results are anticipated to be influenced by groundwater conditions and geologic material lithologies; both impact development of karst. Seismic velocity profile results are anticipated to be influenced by geologic material strength; material strength can be significantly degraded by karst activity.

The Coconino sandstone is primarily of Aeolian origin. Given both a deep groundwater table and a rock fabric largely lacking in conductive clay particles, high resistivities can be anticipated in the upper subsurface consisting of the Coconino. Lower resistivities can be anticipated in underlying shales at the top of the underlying Corduroy Member. Thus, deep Wenner array resistivity soundings can be anticipated to encounter a significant, deep high resistivity horizon underlain by a low resistivity horizon. An estimate of thickness of the overlying Coconino might be interpreted from resistivity sounding results.

Seismic velocity relates quantitatively to material modulus, and thus is strongly related to geologic material strength. Since shear wave (s-wave) velocity is minimally influenced by saturation, s-wave velocity is an indicator of material strength below the groundwater table. An s-wave velocity profile may be estimated using surface wave methods such as ReMi. As a well-known canyon cliff-forming formation on the Colorado Plateau, the Coconino sandstone can be anticipated to have high seismic velocity when relatively competent. However, if significant dissolution in underlying salt beds result in a loss of support under the Coconino, distortion, fracturing and perhaps even brecciation and collapse of the otherwise intact formation into the underlying void space forming sinkholes, is anticipated. High measured s-wave velocities are anticipated in the Coconino where underlying dissolution collapse has not occurred and the formation is relatively competent. Low measured s-wave velocities are anticipated in the Coconino where underlying dissolution has occurred and the overlying formation has been fractured, distorted or brecciated.

\section{Initial Geophysical Reconnaissance}

Initial geophysical reconnaissance at the Section 3 feature was performed by a small group of volunteers on 15 September 2012. Two each deep Wenner array resistivity and ReMi surface wave soundings were completed at locations shown in Figure 2. Based on existing data interpretation, Soundings Location 1 was generally assumed to be outside the area of active subsidence to attempt to provide a baseline for the subsurface geologic profile without influence of local subsidence. Soundings 
Location 2 was centered near the RTK base in the area of greatest current subsidence magnitude to attempt to provide some initial characterization of geomaterial properties in the area of active subsidence.

\section{Resistivity Measurements}

Resistivity measurements were made using the Wenner method. Four electrodes are set into the ground, making electrical contact with the earth, along a line at equal spacing. An electrical current is applied to the two outer electrodes, and the voltage difference in the resulting electric field is measured at the two inner electrodes. An apparent resistivity, a function of voltage, current and geometry, is determined for that electric field. The electric field forms within a roughly hemispherical volume of earth with radius of the electrode spacing. A sounding consists of a series of progressively larger electrode spacing measurements that sample progressively deeper volumes of earth. The depth of investigation is difficult to assess, but is less than the largest electrode spacing. Interpretation consists of developing mathematical models of layer thicknesses and resistivities that is matched to the measured resistivities.

An L-and-R Ultra-Minires resistivity meter was used with resistivity electrode spacings of $1.5,3,6,15$, 30, 60, 101, 152, 229 and 305 meters to complete the resistivity soundings. Electrical contact between the stainless steel electrodes and earth was established by driving the electrode into the dry to very slightly moist ground, removing it, filling the hole with water, and then re-driving the electrode into the hole. Markings on cables and reels were used to set electrode positions at the longer electrode spacings.

\section{Resistivity Interpretation Results}

Interpretations of the two resistivity soundings were consistent with high resistivity unsaturated rock lacking significant fines within the rock fabric to depths of about 100 to 130 meters. Below a thin surficial horizon, interpreted resistivity at Sounding R-1, located outside the active subsidence area, ranged from about 4,400 to $8,100 \mathrm{ohm}-m e t e r s$ in assumed Coconino sandstone above the groundwater table. Below a depth of about 128 meters, the interpreted resistivity dropped to about $47 \mathrm{ohm}-\mathrm{m}$. This significant resistivity drop may reflect saturation in the Coconino below the water table. Alternatively, it may indicate the top of the underlying Corduroy Member, although a resistivity of $47 \mathrm{ohm}-\mathrm{m}$ is typically high for a shale below the water table. It may also indicate a combination of a relatively thin section of saturated Coconino and somewhat deeper underlying low resistivity shale. At a minimum, the top of the Corduroy Member can be interpreted to lie at a depth greater than about 128 meters at Sounding 1. It must be understood that the resistivity interpretations result in non-unique solutions and assume ideal geometric models such as horizontally uniform layers or horizons.

Resistivity Sounding 2, located in the active subsidence area, had similar interpreted results (Figure 5) as Sounding 1 . The interpreted top of the lower resistivity horizon, at a depth of about 111 meters, was shallower at Sounding 2 than the 128 meter depth at Sounding 1. Subsidence along the Sounding 2 profile might be a possible contributor to explain a shallower depth to lower resistivity. Discarding the measurement at 15 meter electrode spacing, the interpretation curve fit to the field data was excellent, as shown in Figure 5. An anomalous reading at the 15 meter electrode spacing could be explained by an observed open fissure exposing shallow bedrock near the northern outer current electrode. Such a feature extending into the subsurface could influence (partially blocking) the current path near that electrode.

\section{ReMi Seismic Measurements}

Refraction Microtremor (ReMi) is a seismic surface (Rayleigh) wave method (Louie, 2001; Optim, 2004) that utilizes surface wave dispersion physics to characterize the subsurface as a vertical 1-dimensional s-wave profile. Like vertical sounding using resistivity,

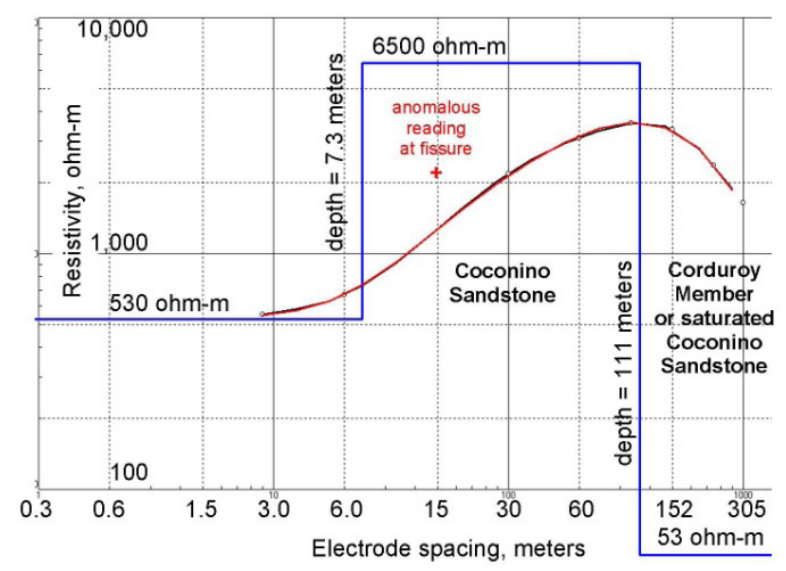

Figure 5. Interpretation of resistivity Sounding 2 showing apparent resistivity measurements, curve fitting and resulting interpretation. 
the interpretation process leads to non-unique solutions. If available, other subsurface information can help to constrain the non-unique solutions. Surface wave methods can characterize the subsurface profile below velocity reversals and below the water table where compression wave methods (such as standard seismic refraction) can be severely limited.

ReMi can also be used in naturally and culturally noisy environments and can use ambient ground vibration as a passive surface wave energy source. Depth of investigation is constrained by the wavelength penetration of the surface waves into the earth; depths of investigation greater than 100 meters are often attainable if sufficiently low frequency surface wave energy is available. Transcontinental railroad traffic passing through the Holbrook basin several kilometers to the north of the study site provided a ready source of ambient low frequency surface wave energy.

The field procedure included laying out cabling for a 24-geophone array at 7.6 meter geophone spacing, and setting and leveling the 24 low frequency $(4.5 \mathrm{~Hz})$ geophones. Overall array length was 175 meters. Arrays were oriented roughly northnortheast to point towards the general direction of the distant railroad energy source. A 24-channel seismograph was used to collect 12 or 24 second ambient surface wave datasets at sampling intervals of 1 or 2 milliseconds. Since railroad traffic was many kilometers away, geophone channel gains were set to high amplification; no filtering was applied during data collection.

The interpretation at ReMi Sounding 1 outside the area of active subsidence is presented in Figure 6. An immediate difference of the ReMi interpretation and general concept of the geologic profile is a relatively low surface wave velocity in the upper 50 meters of the subsurface. At a velocity less than 700 meters per second $(\mathrm{m} / \mathrm{s})$, the upper 50 meters of the Coconino sandstone is not a relatively competent, high strength rock material. At best, it might be considered equivalent to a very soft rock, but may exhibit soil-like characteristics (from an engineering perspective). Below about 50 meters, the greater than $2,000 \mathrm{~m} / \mathrm{s}$ surface wave velocity is indicative of competent rock.

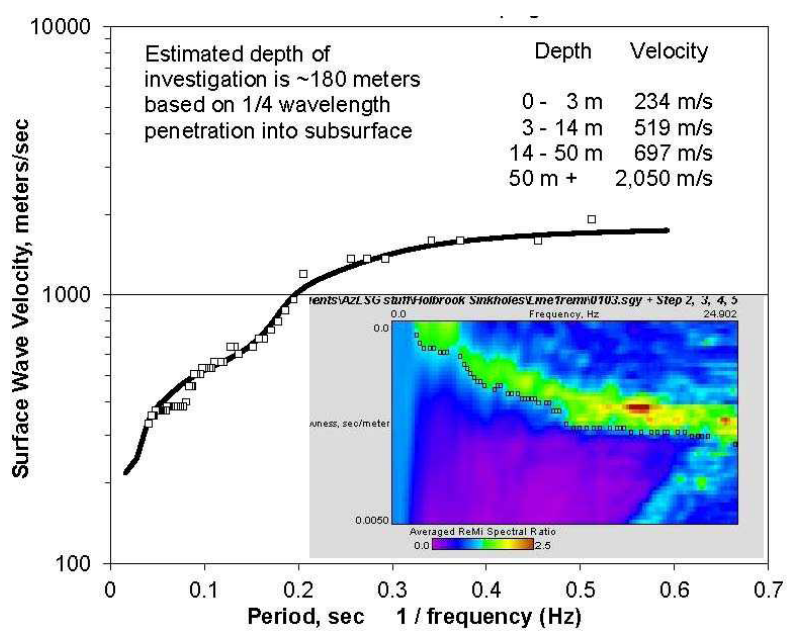

Figure 6. Interpretation of ReMi Sounding 1 showing spectral amplitude as a function of surface wave velocity and frequency, dispersion curve fitting and resulting interpretation.

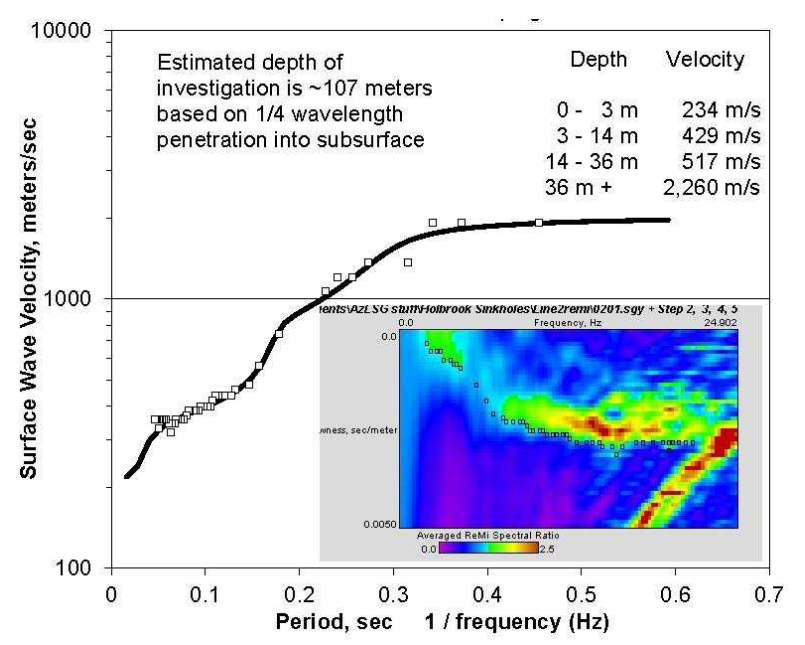

Figure 7. Interpretation of ReMi Sounding 2 showing spectral amplitude as a function of surface wave velocity and frequency, dispersion curve fitting and resulting interpretation.

The interpretation at ReMi Sounding 2 within the area of active subsidence is presented in Figure 7. The relatively low surface wave velocity is in the upper 36 meters of the subsurface, but has an even lower velocity of about $520 \mathrm{~m} / \mathrm{s}$. From an engineering perspective, it might be considered equivalent to a very dense or cemented soil. Below about 36 meters, the greater than $2,000 \mathrm{~m} / \mathrm{s}$ surface wave velocity is indicative of competent rock. Thus, a relatively competent rock portion of the Coconino sandstone is interpreted to be present at the Sounding 2 location in the area of most active subsidence. 


\section{Geophysical Anomalies}

Even though quantitative analysis may require ignoring or discarding some anomalous data, anomalies in geophysical data can provide critical information to assist in understanding subsurface conditions. As was previously noted, a resistivity reading at Sounding 2 was discarded for interpretation due to the presence of an open fissure (Figure 8) near an outer electrode. The Sounding 2 ReMi seismic array was deployed in this same area. Anomalous signal loss in ReMi data from this location is shown in Figure 9. A coherent surface wave signal with a frequency of about $4.4 \mathrm{~Hz}$ appeared to be blocked between traces 9 and 10 from the right in Figure 9 on the trace printout. That type of attenuation anomaly is consistent with an open fissure in the subsurface with sufficient continuity and depth to block the signal propagation. From the interpretation shown in Figure 7 , surface wave velocity at $4.4 \mathrm{~Hz}$ is about $1,000 \mathrm{~m} / \mathrm{s}$, resulting in a wavelength of about 227 meters. Since most of the surface wave energy propagates within the upper quarter to half wavelength of the surface, such attenuation could indicate an open fissure that may extend well into the subsurface.

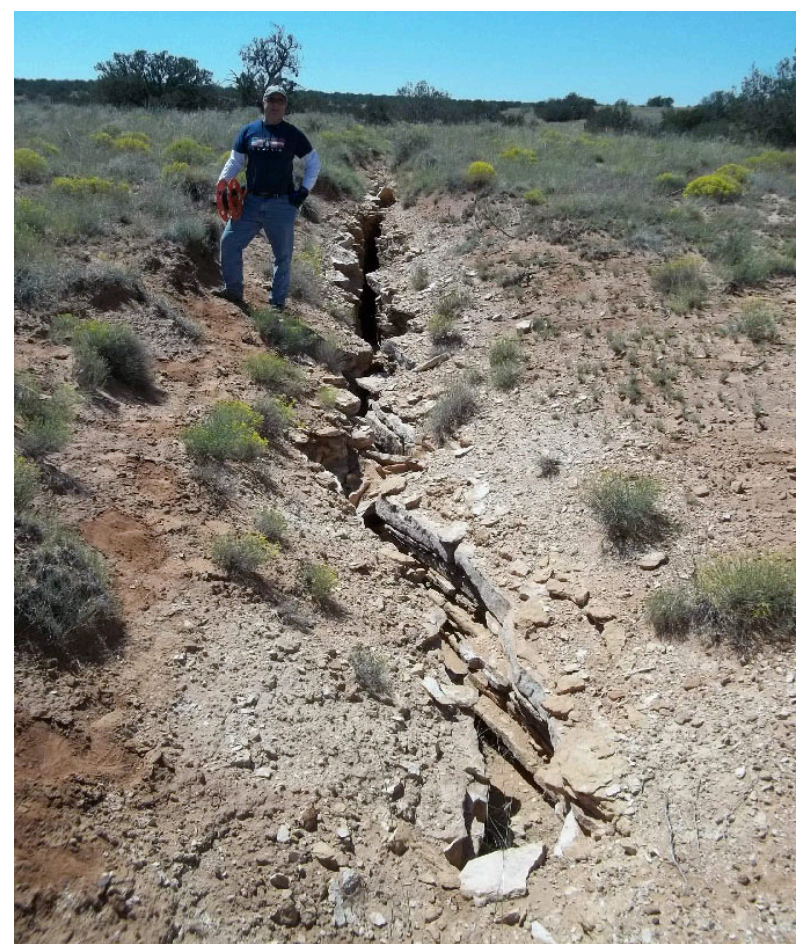

Figure 8. Open fissure along surface geophysical arrays alignment. Note near-surface bedrock and relatively uneroded adjacent soil surface that indicates recent fissure development.

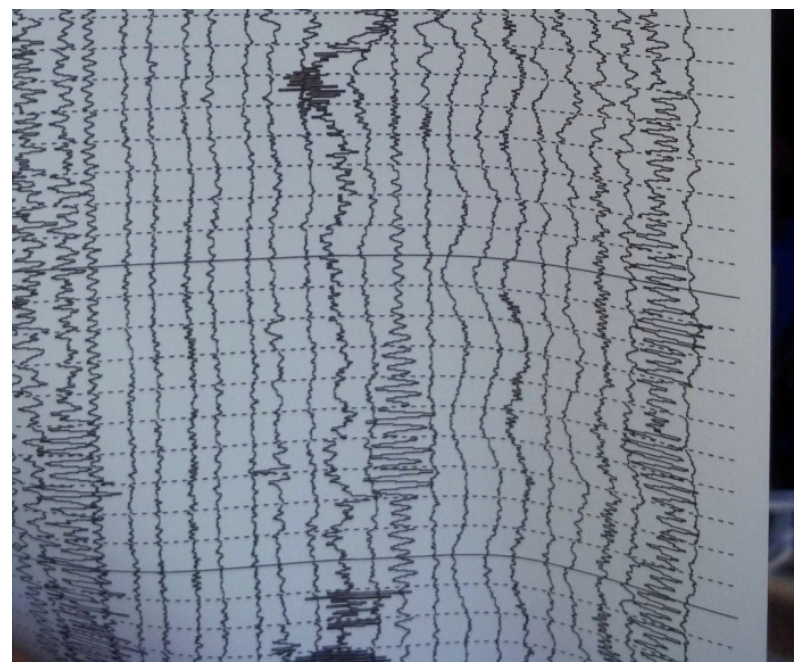

Figure 9. Anomalous surface wave signal loss in ReMi Sounding 2 field data at open fissure. All geophones are set at equal gains (84 db). Note loss of coherent signal from right to left between the 9th and 10 th traces.

\section{Discussion}

Initial geophysical reconnaissance has begun to illuminate subsurface conditions at the Section 3 feature to understand the active subsidence documented by InSAR and possible previous subsidence indicated by the RTK elevation profile survey. However, initial results have also raised questions about assumptions of subsidence mechanisms. The interpretation of a high velocity horizon at Sounding 2, consistent with relatively competent Coconino sandstone in the area of highest current subsidence and the edge of greatest apparent subsidence, does not indicate significant local disruption of the geologic profile from dissolution in the underlying salt.

Is there an alternative explanation for the apparent 12 meters of subsidence that may have occurred just to the south of the highest current subsidence? The shallower low velocity upper Coconino horizon might provide an explanation. If differences in seismic velocity in the upper 36 to 50 meters inside (lower velocity) and outside (higher velocity) the active subsidence are correct, changes in the weak rock fabric similar to collapsible soils might explain some of the apparent subsidence. As described previously (Johnson, 1962), the Coconino sandstone has a cemented structure. If that cemented structure is disrupted, the particles could collapse into a more dense structure, resulting in surface subsidence. 
Seismic velocity can be related to geo-material porosity and modulus based on concepts of Percolation Theory as described by Sahimi (1994). Rucker (1998, 2000, 2008), has developed these relationships for cohesionless granular, fractured or jointed geo-materials that behave as 'physical gels', where material mass particle contact points freely move (roll) relative to each other. When adjacent particles are cemented, bonded or welded in 'chemical gels' such as welded tuff or unfractured limestone, they are not free to move (roll) relative to each other. Relationships of surface wave velocity to a geo-material mass density are presented in Figure 10; data points are discussed in Rucker (2008).

The ReMi Sounding 1 horizon with surface wave velocity of $700 \mathrm{~m} / \mathrm{s}$ at depths of 14 to 50 meters, may behave as a chemical gel material that, although relatively low density, has an intact cemented rock fabric relatively unaffected by subsidence or karst activity. It might have a mass density (Figure 10) as low as perhaps about $1,400 \mathrm{~kg} / \mathrm{m}^{3}$. The same horizon within the subsidence area may have suffered disruption of the rock fabric as the rock mass has been stressed and degraded, perhaps through mass movement and or weathering induced through fissures. With loss of cementation or bonding, the rock material structure might behave as a physical gel material that has consolidated or collapsed into a more dense structure. As a physical gel material, the analogous ReMi Sounding 2 horizon, with surface wave velocity of $520 \mathrm{~m} / \mathrm{s}$ at depths of 14 to 36 meters, might have a mass density (Figure 10) of about $1,950 \mathrm{~kg} / \mathrm{m}^{3}$. The change from chemical to physical gel behavior could cause the horizon volume to decrease to roughly $(1,400 / 1,950=) 71$ percent of its original volume. Since 71 percent of 50 meters is about 36 meters, a change in the rock material from a chemical to a physical gel behavior is consistent with the difference in the interpreted horizon thickness. Also, the difference of 50 meters and 36 meters is 14 meters, which is close to the roughly 12 meters of apparent subsidence measured by the RTK elevation survey.

\section{Limitations of 1-Dimensional Methods}

Charaterization of karst can be a highly complex and variable 3-dimensional process. The applicability of relatively simple 1-dimensional 'sounding' methods may be, in part, a function of other available information about a karst site and the scale of measurements being made compared to the scale of the phenomena being evaluated. Scale is a primary variable. When a target

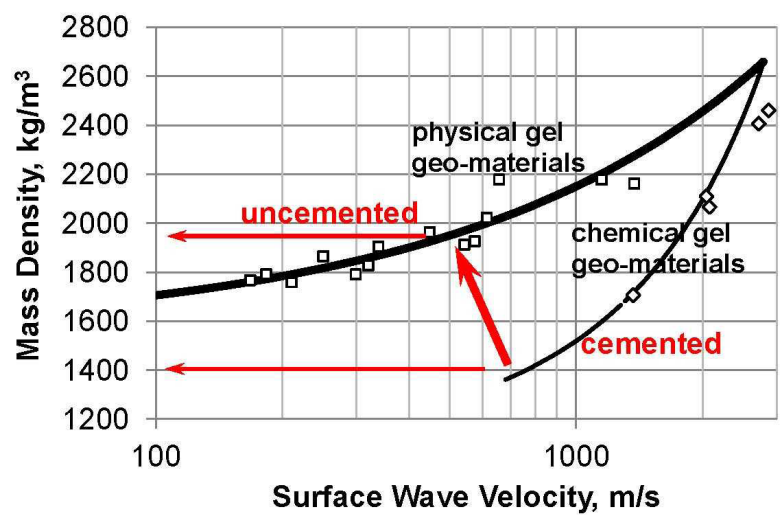

Figure 10. Percolation Theory-based relationships between seismic velocity and mass density for physical gel and chemical gel geo-materials. When bonds in a chemical gel material are disrupted, that material can revert to a physical gel as shown.

is small relative to the capability of the geophysical measurement, potentially critical variations within the target cannot be assessed. However, for a target area that is large relative to the capability of the geophysical measurement, a series of 1-dimensional measurements can be performed to develop some understanding of the target in 2- or 3 dimensions.

If nearby borehole or well logs, or other detailed data, are available at a site, then surface geophysical soundings may be of limited value, or may have value in verifying whether conditions are similar to or change from nearby known conditions. When no other local subsurface geologic information is available, reconnaissancelevel geophysical soundings may be a primary feasible economic means to obtain preliminary subsurface information to begin a site investigation.

\section{Conclusions and Recommendations}

InSAR has allowed the identification of in-progress subsidence in a geologic setting of probable dissolution-induced subsidence and karst development. Straightforward surficial survey and simple surface geophysical measurements have been applied to initiate a baseline of data to improve understanding of possible subsidence and karst mechanisms. Initial results from these measurements indicate the likelihood of complex, multiple and subtle processes at work at the Section 3 feature, and by inference, other karst areas within the Holbrook Basin.

The authors recommend that a continuing, possibly informal program of mapping, monitoring and 
measurements proceed at this feature. Detailed mapping of surficial fissures, pressure ridges and dip and strike trends of exposed bedrock should be performed and analyzed in a context of local topography and InSAR-derived patterns of current active subsidence. Such tasks could be incorporated into university-level geology class or club activities and other knowledgeable, technically capable volunteer groups. Further simple surface geophysics might then continue to be strategically deployed based on improved knowledge of subsidence and karst-related features and continuing InSAR monitoring. Due to cost, land ownership constraints and the absence of an urgent geohazard condition, future exploratory drilling is not foreseen at the Section 3 feature.

Results presented here are an initial reconnaissance effort to begin to understand the Section 3 feature. As information concerning this feature increases through further investigation and monitoring, knowledge and understanding of the feature and the mechanisms acting on it will improve. Hypotheses of subsidence behavior can be developed, tested and refined. Knowledge and experience gained by such a program, even if informal, will further demonstrate the value of incorporating multiple tools and approaches, including integrated simple surface geophysics, for characterization and monitoring of subsidence and karst.

\section{Acknowledgements}

The authors would like to acknowledge the continuing support of Brian D. Conway and ADWR with the InSAR data and processing, and survey support, with the assistance of Joseph P. Cook with the Arizona Geological Survey, that has made this project possible.

\section{References}

Arizona Department of Water Resources (ADWR). 2012. Groundwater Site Inventory database [cited 2012 November 4]. Available from: https://gisweb. azwater.gov/waterresourcedata/

Conway BD, Cook JP. 2013. Monitoring evaporite karst activity and land subsidence in the Holbrook Basin, Arizona using Interferometric Synthetic Aperture Radar (InSAR). 13th Sinkhole Conference, Carlsbad, NM. In press.

Johnson PW. 1962. Water in the Coconino Sandstone for the Snowflake-Hay hollow area, Navajo County, Arizona. US Geological Survey WaterSupply Paper 1539-S.
Louie JL. 2001. Faster, better, shear-wave velocity to 100 meters depth from refraction microtremor arrays. Bulletin of the Seismological Society of America 91: 347-364.

Optim 2004. SeisOpt@ReMiTM Version 3.0. Optim LLC, UNR-MS 174, 1664 N. Virginia St, Reno NV, 89557-0141 USA

Neal JT, Colpitts R, Johnson KS. 1998. Evaporite karst in the Holbrook Basin, Arizona. In: Borchers JW, editor. Land Subsidence, Case Studies and Current Research. Belmont (CA): Star Publishing Co. p. 373-384.

Rucker ML. 1998. Seismic velocity in cohesionless granular deposits. In: Robertson PK, Mayne PW, editors. Geotechnical Site Characterization, 1st International Conference on Site Characterization. Rotterdam (NE): A.A. Balkema. p. 509-514.

Rucker ML. 2000. Estimating earthwork factors for roadcuts using surface geophysics. In: Girard J, Liebman M, Breeds C, Doe T, editors. Pacific Rocks 2000. Rotterdam (NE): A.A. Balkema. P. 709-714.

Rucker ML. 2008. Estimating in-situ geo-material mass density, modulus and unconfined compressive strength from field seismic velocity measurements. Highway Geophysics - Nondestructive Evaluation Conference, Charlotte, NC, Dec. 1-4.

Sahimi M. 1994. Applications of Percolation Theory. Bristol (PA): Taylor \& Francis. 
